\section{QTL mapping of spike fertility index in bread wheat}

\section{María Pía Alonso ${ }^{1}$, Leonardo Sebastián Vanzetti², Juan Manuel Crescente ${ }^{2}$, Nadia Estefanía Mirabella ${ }^{3}$, Juan Sebastián Panelo ${ }^{3}$ and Ana Clara Pontaroli ${ }^{*}$}

\begin{abstract}
Spike fertility index (SF) is a trait easily measured at maturity and strongly associated with the number of grains per unit area. In order to identify genomic regions involved in SF control, a biparental (Baguette $10 \times$ Klein Chajá) population of 80 recombinant inbred lines (RIL) was used. Seven field trails were conducted to determine the SF BLUP value per RIL. RILs were genotyped using a commercial chip (Axiom ${ }^{\circledR} 35 K$ SNP Wheat Breeder's Array, Affimetrix). A linkage map was constructed with 857 SNP markers, and SF QTL mapping was performed. The narrow-sense heritability of SF was 0.89 . Three genomic regions (QTL) associated with SF were found on chromosomes $2 D, 4 A$, and $7 A$. The proportion of genetic variation explained by these three $Q T L$ was $32 \%$, with no significant epistatic interaction between QTL.
\end{abstract}

Keywords: Spike fertility index, QTL mapping, additive effects, BLUP.

\section{INTRODUCTION}

Bread wheat (Triticum aestivum L.) is one of the most important crops in the world. Given the current and future scenario of increased global demand for grains, breeding efforts must concentrate on improving grain yield (CIMMYT 2019). The identification of specific and efficient selection criteria, as well as advances in knowledge of the genetic and molecular basis of yield and yield components, will allow an increase in genetic gain.

The spike fertility index (SF), i.e., the number of grains per $\mathrm{g}$ of spike chaff [also termed "fruiting efficiency" (Ferrante et al. 2012)], has been widely proposed as a selection criterion in breeding programs (Slafer et al. 2015, Alonso et al. 2018, Fischer and Rebetzke 2018, Valvo et al. 2018, Gerard et al. 2019) mainly due to its association with number of grains per unit area (Abbate et al. 1998, Foulkes et al. 2015, Ferrante et al. 2017).

However, the method of reference for determination of the spike fertility index, first described by Fischer (1984), uses spike dry weight at anthesis, making it a destructive method that is highly sensitive to the exact phenological stage in which measurement is carried out (Fischer and Rebetzke 2018). Abbate et al. (2013) proposed the alternative of the spike fertility index measured at maturity (i.e., calculated with spike chaff weight at maturity), as a selection criterion in breeding programs. This trait has been then shown to have good association with NG (Alonso et al. 2018, Pradhan et al. 2019) and moderate to
Crop Breeding and Applied Biotechnology 21(1): e34402113, 2021 Brazilian Society of Plant Breeding. Printed in Brazil http://dx.doi.org/10.1590/198470332021v21n1a3

\author{
*Corresponding author: \\ E-mail: pontaroli.ana@inta.gob.ar \\ (i) ORCID: 0000-0002-2605-7668
}

Received: 10 March 2020 Accepted: 15 September 2020 Published: 31 January 2021

${ }^{1}$ Universidad Nacional de Mar del Plata, Facultad de Ciencias Agrarias, Unidad Integrada Balcarce/ Instituto Nacional de Tecnología Agropecuaria (INTA) and Consejo Nacional de Investigaciones Científicas y Técnicas (CONICET), Estación Experimental Agropecuaria Balcarce, Ruta 226, km 73.5, CC 276 (7620), Balcarce, Argentina

${ }^{2}$ INTA and CONICET, Grupo Biotecnología y Recursos Genéticos, Estación Experimental Agropecuaria Marcos Juárez, Ruta 12 s/n, CP 2850, Marcos Juárez, Córdoba, Argentina ${ }^{3}$ Universidad Nacional de Mar del Plata, Facultad de Ciencias Agrarias, Unidad Integrada Balcarce/ INTA, Estación Experimental Agropecuaria Balcarce, Ruta 226, km 73.5, CC 276 (7620), Balcarce, Argentina 
high heritability (Martino et al. 2015, Alonso et al. 2018, Pretini et al. 2020a), as well as transgressive segregation and a low genotype $\times$ environment interaction (Martino et al. 2015, Mirabella et al. 2016, Alonso et al. 2018).

In addition, because it is a simpler, non-destructive method, it is ideal for use as a high- throughput measurement method for selection in early generations. Although there are no conclusive results of how accurate SF at maturity is in estimating SF at anthesis, Slafer et al. (2015) suggest that there are indications of a small overestimation of the SF at maturity, due to the fact that spike dry matter may increase from anthesis to maturity. In this respect, Pretini et al. (2020a) observed instability in this estimator in different environments. However, Abbate et al. (2013) found high association between these two indices ( $r>0.7$ ), and Alonso et al. (2018), Fischer and Rebetzke (2018), and Pradhan et al. (2019) detected a positive association between SF at maturity and NG. Furthermore, Terrile et al. (2017) and Alonso et al. (2018) found that selection for high SF resulted in stable and positive genetic gain in grain yield.

Most important agronomic traits in cereals are quantitatively inherited and the genes underlying their variation have been difficult to detect (Neumann et al. 2011). Several studies carried out during the last 20 years have pursued identification of quantitative trait loci (QTL) of yield and yield-related traits in mapping populations (Börner et al. 2002, McCartney et al. 2005, Kumar et al. 2007, Neumann et al. 2011, Hussain et al. 2017). However, there is little information in the literature about mapping QTL for SF. The first evidence in the literature revealed QTL associated with SF at anthesis based on genome wide association studies (GWAS) in chromosomes 2A, 2D, 4D, 5A, and 7A (Basile et al. 2019, Gerard et al. 2019). As for SF at maturity, Guo et al. (2017) found a QTL on chromosome $2 A$, with a relatively small effect. Ramirez et al. (2018) reported significant yet small effects of $P p d-B 1$ and $P p d-D 1$ on SF at maturity that were independent from those on the flowering date. Recently, a GWAS conducted by Pradhan et al. (2019) allowed identification of 15 markertrait associations (MTAs) with SF in chromosomes 1B, 3B, 4A, 6B, and 7D. Fourteen of these MTAs were located in four regions apparently involved in abiotic and biotic stress response pathways. Recently, Pretini et al. (2020b) validated two QTL for SF in a doubled haploid mapping population, derived from Baguette19 and BioINTA2002. Those QTL were located in chromosomes $3 \mathrm{~A}$ and $5 \mathrm{~A}$. In summary, evidence of the existence of genomic regions significantly associated with SF at maturity is only fragmentary and it has been scarcely addressed through the use of biparental populations.

Nevertheless, extensive work has been carried out in a recombinant inbred line (RIL) population derived from two Argentinian cultivars (Baguette 10 and Klein Chajá) contrasting for SF and other yield-related traits. In this population, the mode of inheritance of SF (Martino et al. 2015, Mirabella et al. 2016, Alonso et al. 2018), the possibility of using SF as a selection criterion in breeding for grain yield (Alonso et al. 2018), and the existence of significant molecular markerSF associations [in a preliminary study by Panelo et al. (2019)] have been established. Therefore, the objective of this study was to identify QTL associated with SF in this population, evaluated in Balcarce and Marcos Juarez, Argentina.

\section{MATERIAL AND METHODS}

\section{Plant material}

Quantitative trait loci mapping was conducted using a population of 80 RIL from the cross between 'Baguette 10' and 'Klein Chajá', both Argentinian semi-dwarf hard spring wheat varieties released in 2000. 'Baguette 10' (B10; pedigree ARCHE/GENIAL) has been classified as having high SF, whereas 'Klein Chajá' (KCJ; pedigree NINJING/3/BUC'S'//H697/ $\mathrm{DKBL}$ ) has been classified as having low SF (Martino et al. 2015). Both cultivars have similar intermediate growth cycles and are well adapted to Argentinian wheat-growing areas. They show several differences in spike architecture: B10 has a compact, short, dense spike, with very thin glumes and rachis, whereas KCJ has a longer, laxer spike with a large number of spikelets and grains and a heavy chaff structure (Martino et al. 2015, Alonso et al. 2018).

\section{Phenotypic evaluation}

Six field experiments were carried out at the Balcarce (BCE) Experimental Station (lat 37ㅇ 45' S; long 55 18' W, alt $130 \mathrm{~m}$ asl) of the Instituto Nacional de Tecnología Agropecuaria (INTA), Buenos Aires Province, Argentina, and one experiment was carried out at the Marcos Juárez (MJ) Experimental Station (lat 32 ${ }^{\circ} 43^{\prime} \mathrm{S}$; long $62^{\circ} 06^{\prime} \mathrm{W}$, alt $112 \mathrm{~m}$ asl), INTA, Córdoba Province, Argentina. General crop management of experiments 1-3 has been described in Alonso et al. (2018); the remaining experiments were conducted similarly except for the fact that no irrigation was applied. Specific information on each experiment is presented in Table 1. 
Table 1. Field experiments carried out at Balcarce (BCE) and Marcos Juárez (MJ), Argentina, between 2013 and 2017

\begin{tabular}{llccccc}
\hline Exp. & Year & Location & No. of blocks & Sowing date & Plot description & Growing conditions \\
\hline 1 & 2013 & BCE & 2 & June $27^{\text {th }}$ & Three 5-m length rows with 0.2 m between rows & Irrigated \\
2 & 2014 & BCE & 2 & July $24^{\text {th }}$ & Seven 5-m length rows with 0.2 m between rows & Irrigated \\
3 & 2015 & BCE & 2 & July $15^{\text {th }}$ & Seven 5-m length rows with 0.2 m between rows & Irrigated \\
4 & 2016 & BCE & 2 & June $20^{\text {th }}$ & One 1-m length row & Rainfed \\
5 & 2016 & BCE & 2 & July $10^{\text {th }}$ & One 1-m length row & Rainfed \\
6 & 2017 & BCE & 2 & June 19th & One 1-m length row & Rainfed \\
7 & 2017 & MJ & 1 & June $25^{\text {th }}$ & Three 1-m length rows, with 0.2 m between rows &
\end{tabular}

The heading, anthesis, and physiological maturity dates of each plot were registered in the field when $50 \%$ of the spikes reached those stages, using the Zadoks scale (Zadoks et al. 1974). Physiological maturity was determined as loss of green from the peduncle. As expected from previous data (Martino et al. 2015, Alonso et al. 2018), each of the phenological stages was concentrated within one week for $>90 \%$ of the RILs and within 10 days for the entire population (data not shown). Weather conditions were recorded daily with a standard meteorological station located at each experimental station.

At maturity, 15-20 spikes were drawn at random from each plot. When seven-row plots were used, only the five central rows were sampled. Spikes were cut at the lowest spikelet level, counted, weighed, and threshed. Spike chaff dry weight (g) was calculated as the difference between total spike dry weight (i.e., before threshing) and total grain weight. Grains were counted using an electronic counter. Then, SF (grains $\mathrm{g}^{-1}$ ) was calculated as the quotient between number of grains and spike chaff dry weight (Abbate et al. 2013).

\section{Linkage map construction}

Eighty RIL and the parents of the population were genotyped with the Axiom ${ }^{\circledR} 35 \mathrm{~K}$ SNP Wheat Breeder's Array (Affimetrix) (Allen et al. 2017). For genotyping, genomic DNA was extracted from a single seedling leaf tissue according to Haymes (1996). Only those polymorphic SNPs showing less than $10 \%$ missing data and segregation distortion under $20 \%$ were considered for construction of the linkage map. In addition, independent genotyping of the population with two functional markers for the Vrn-A1 (Yan et al. 2004) and Rht-D1 (Ellis et al. 2002) genes was added to the analysis. Those markers that had identical or compatible segregation in the whole population were grouped using the merger. pysoftware (https://github.com/juancrescente/Imap) in order to minimize the redundant information. Once the markers were grouped, the linkage map was constructed using the R/qtl software (Broman et al. 2003). Genetic distances between the markers were calculated based on the Haldane mapping function. Throughout the 21 wheat chromosomes, several SNPs were anchored to the Ref Seq 1.0 genome assembly (Appels et al. 2018). Relationships between the genetic and physical positions of the SNPs were then established.

\section{Statistical analysis and QTL detection}

Linear mixed models were fitted for SF using the Ime function from the $n$ Ime package (Pinheiro et al. 2013) of the $\mathrm{R}$ software (R Core Team 2015). The models included replications within environments (years and/or sowing dates within a year) and environments as fixed factors, and genotypes and the genotype $\times$ environment interaction as random factors. The critical level of significance used was 0.05 . Variance components and narrow-sense heritability were estimated according to Alonso et al. (2018).

Quantitative trait loci analysis was conducted with Composite Interval Mapping (CIM) using QTL Cartographer software (Wang et al. 2012a). Best linear unbiased predictors (BLUP) for each RIL, obtained from the mixed model, were used in QTL analysis. Threshold was calculated with 500 permutations and a 0.05 critical level of significance. Up to ten markers showing the highest $\mathrm{F}$ value after the forward-backward stepwise regression analysis were added as cofactors in the CIM step [model 6, using a moving window size of 10 centiMorgan (cM) and a walking speed of $1 \mathrm{cM}$ ]. The most likely position of the QTL was determined as the point with the maximum logarithm of the odds (LOD) score. The confidence interval (Cl) of each QTL was defined as the map interval corresponding to a LOD-2 decrease to each side of the LOD 
peak. A linear fixed model was fitted to calculate the additive effect $(a)$ of each QTL. The model included QTL and QTL $\times$ QTL interaction effects, and BLUPs were used as phenotypic values. The proportion of the genetic variation explained $\left(R^{2}\right)$ by all QTL was obtained from this model. The critical level of significance used was 0.05 .

The physical position of QTL was considered to be that of the marker nearest the peak LOD score. Using the flanking sequence for each SNP marker, provided by the chip manufacturer (Axiom, Affimetrix), a local alignment was performed using the BLAST algorithm (Altschul et al. 1990) against the reference sequence IWGSC RefSeq v1.0 of the bread wheat genome (Appels et al. 2018) to verify its position.

Haplotype was constructed for each RIL using the marker associated with the peak of the maximum LOD-score of each QTL identified. Haplotype proportions were tested with the Chi-square test ( $p$ value $=0.05, \mathrm{df}=7$ ). Due to heteroscedasticity between haplotype groups, Welch's ANOVA test was carried out using userfriendlyscience package (Verboon et al. 2018) of the R software, and haplotype differences were estimated using the Games-Howell nonparametric test.

\section{RESULTS AND DISCUSSION}

Mean SF in the RIL population was 98.3, 91.9, 89.5, 92.4, 89.5, 90.7, and 101.7 grains $\mathrm{g}^{-1}$ for experiments 1 to 7 , respectively. In each environment, SF values showed a symmetric, bell-shaped distribution with a wide range of variation from $\sim 55$ to $\sim 135$ grains $\mathrm{g}^{-1}$ [partial data is available in Alonso et al. (2018) and Figure S1], whereas the parents showed SF values as expected from previously published data (Alonso et al. 2018 and Figure S1). The relative weight of variance components and heritability were also coincident with previous reports, as genetic, genetic $\times$ environmental, and residual variances were $54.1,9.3$, and 67.2 , respectively, and heritability was 0.89 . These results are in line with previous studies, which showed that SF fit an oligogenic model comprising a few loci with relatively large effects and high heritability (Martino et al. 2015, Mirabella et al. 2016, Alonso et al. 2018); i.e., a high probability of a finite number of markers explaining a considerable proportion of the phenotypic variance. In this study we included data from seven environments, and SF was accurately determined and predicted with BLUPs, which increases the reliability of the QTL significance (Piepho et al. 2008, Segura et al. 2009, Sadok et al. 2013).

This study was carried out with genotypic data from 80 individuals. The genetic linkage map consisted of 368 loci on the 21 chromosomes of bread wheat and spanned $3674 \mathrm{cM}$ (Table S1). These loci included 857 SNP and two functional markers corresponding to the Rht-D1 and $V r n-A 1$ genes. Linkage maps per chromosome are shown in Figure S2. The fact that the functional markers Rht-D1 and $V r n-A 1$ were correctly mapped in the genome validates the mapping procedure. The use of mapping populations of reduced size, as was the case in the present study, may allow detection of QTL with major effects, but limits the detection of additional, small, yet real QTL (Beavis 1998, Vales et al. 2005, Cavalcanti et al. 2012, Wang et al. 2012b). Schön et al. (2004) recommend the use of a conservative threshold, such as the one used here, if the aim of a study is to identify a few large QTL controlling a limited proportion of the genetic variance. On the other hand, the number of SNP markers on each chromosome does not allow restriction of QTL to smaller map distances (Li et al. 2010).

The elucidation of the molecular and genetic basis of yield-related traits can contribute not only to understanding how yield is determined, but also to the development of technologies for speeding up the selection process, leading to high yielding cultivars. In this study, we detected three QTL associated with SF, a trait closely linked to number of grains per unit area, which is the main yield component in bread wheat. Three QTL for SF were detected in chromosomes 2D, $4 \mathrm{~A}$, and 7A (Table 2); the latter two have not been previously reported. All three QTL showed high stability across seven environments, which spanned differences in temperature, water regime, solar radiation, and photoperiod. The proportion of genetic variation explained by these three QTL was 32\%, with no significant epistatic interaction between QTL.

The QTL on chromosome 2D (referred to as $\mathrm{Q}_{\text {sf.bfe.2DL }}$ ) had an additive effect of 7.44 grains $\mathrm{g}^{-1}$, expressed as the difference from the population mean. The donor of the SF-increasing allele was B10 (i.e., the parent with higher SF). The confidence interval of this QTL was $9 \mathrm{cM}$, and the physical position of the SNP marker associated with the peak of the maximum LOD score was 648 Mbp (Table 2).

On chromosome $4 \mathrm{~A}$, the QTL $Q_{\text {sf.bfe.4AL }}$ showed an additive effect of 2.44 grains $\mathrm{g}^{-1}$, with $\mathrm{B} 10$ as the donor parent. Located at $\sim 472 \mathrm{Mbp}$, the confidence interval of $Q_{\text {sf.bfe.4AL }}$ comprised $5.4 \mathrm{cM}$. A third QTL, $Q_{\text {sf.bfe. } 7 \mathrm{~A}}$, was detected in chromosome 
7A donated by B10. $Q_{s f . b f e .7 A}$ showed an additive effect of 1.74 grains $\mathrm{g}^{-1}$, and a greater confidence interval $(15.1 \mathrm{cM})$ in comparison with the remaining two QTL. Regarding its physical position, the SNP marker associated with the peak of maximum LOD was located in $\sim 119 \mathrm{Mbp}$.

Basile et al. (2019) also detected SF QTL in the latter two regions. One of the QTL was located in the vicinity, but not in the same position, of the newly reported $Q_{\text {sf.bfe.4AL }}$. Indeed, the QTL reported by Basile et al. (2019) on chromosome 4A (at $600 \mathrm{Mbp}$ ) was located around $200 \mathrm{Mbp}$ from $Q_{\text {sf.bfe.4AL. }}$. The QTL on chromosome 7A, on the other hand, appears
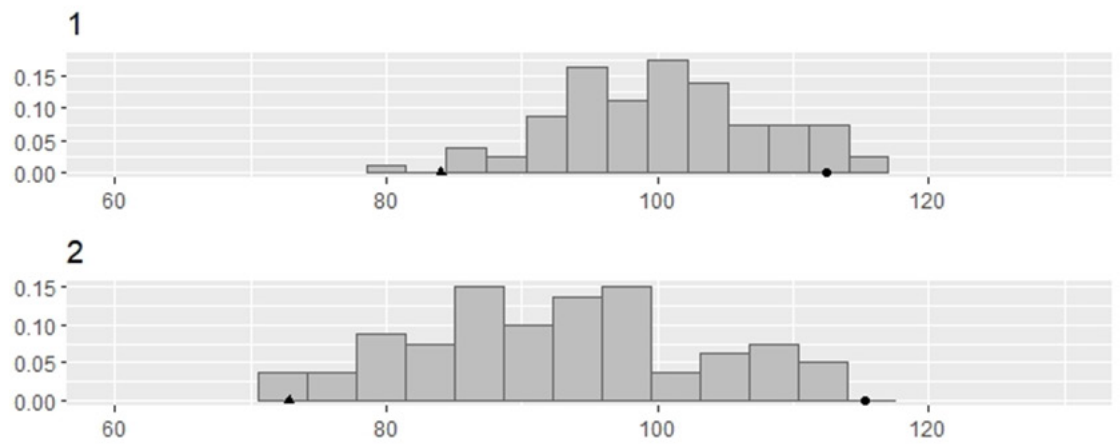

3

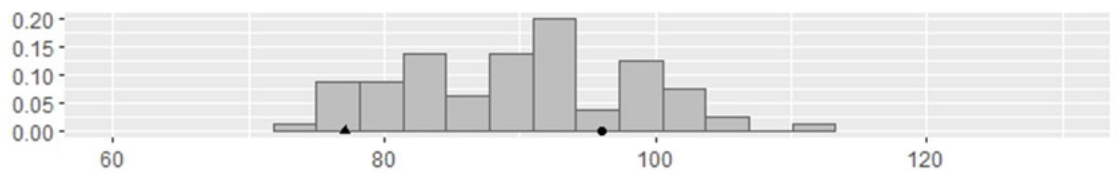

4

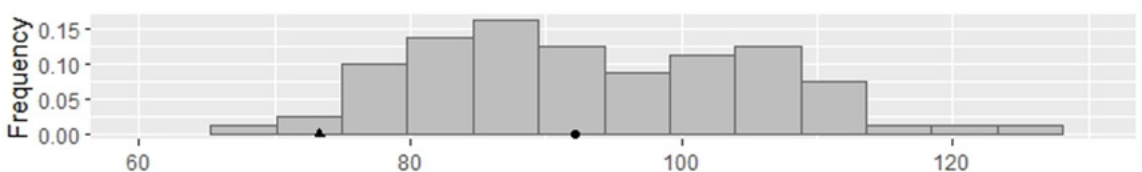

5

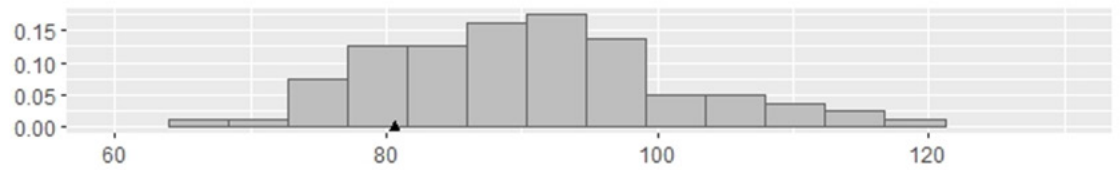

6

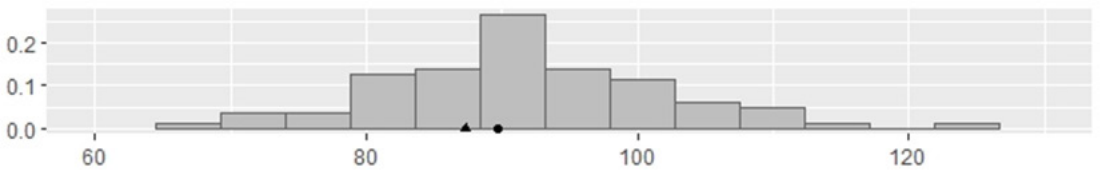

7

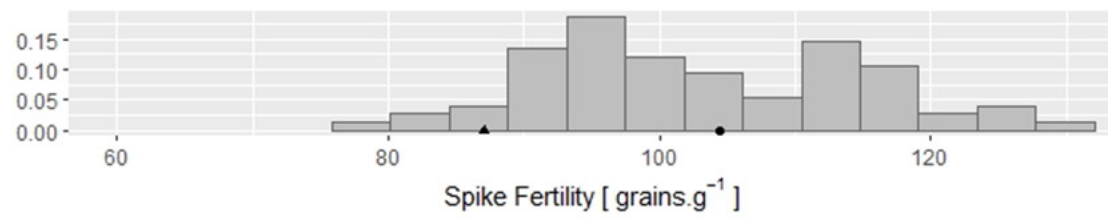

Parental Cultivars • B10 ^ KCJ

Figure S1. Frequency histogram of spike fertility index in the B10xKCJ RIL population (B10/KCJ) as evaluated in seven experiments (1 to 7). 
to colocalize with $Q_{s f . b f e .7 A}$, detected in this study. Guo et al. (2017) proposed two candidate genes for SF and other associated traits, named CONSTANS4 (CO4) and Six-rowed spike 1 (Vrs1), located in chromosome 2AL. Vrs1, also known as GNI-A1, has recently been associated with the number of fertile flowers and grains per spikelet traits (Sakuma et al. 2019, Golan et al. 2019). However, considering the genetic positions of markers associated with CO4, this QTL would not be homoeologous to $Q_{\text {sf.bce.2DL }}$. The genetic position of Vrs1 has not yet been defined in the IWGSC RefSeq v1.0 reference sequence of the bread wheat genome (Appels et al. 2018). As for the QTL mapped by Gerard et al. (2019) on chromosome 2D, the physical position of the associated marker (Kukri_rep_c68068_95) is 641.1 Mb, which is very close to AX-94501170 and AX-95232269 (648 Mb), the SNP marker associated with the peak of maximum LOD of $Q_{\text {sf.bce.2DL }}$ detected in the present study. Gerard et al. (2019) measured SF (fruiting efficiency - FE) at anthesis, not at maturity, as it was done in this study. Abbate et al. (2013) have shown the existence of differences between FE at anthesis and at maturity. Therefore, the QTL detected by Gerard et al. (2019) may not colocalize with $Q_{\text {sf.bce.2DL }}$. None of the QTL found by Pretini et al. (2020b) in chromosomes 3A (685.12 Mbp) and 5A (461.49 Mbp) were present in the B10xKCJ RIL population.

The effect of the Ppd genes, reported by Ramirez et al. (2018) as being associated with SF, could not be evaluated in this population because their parents, B10 and KCJ, are monomorphic for these genes (Vanzetti et al. 2013).

Table S1. Distribution of 857 SNP markers used for linkage map construction. Twenty-one bread wheat chromosomes are listed. Marker\#/Loci\#: number of markers and loci assigned to each chromosome; total length in centiMorgan (cM) of each chromosome; average and maximum spacing of loci in $\mathrm{cM}$

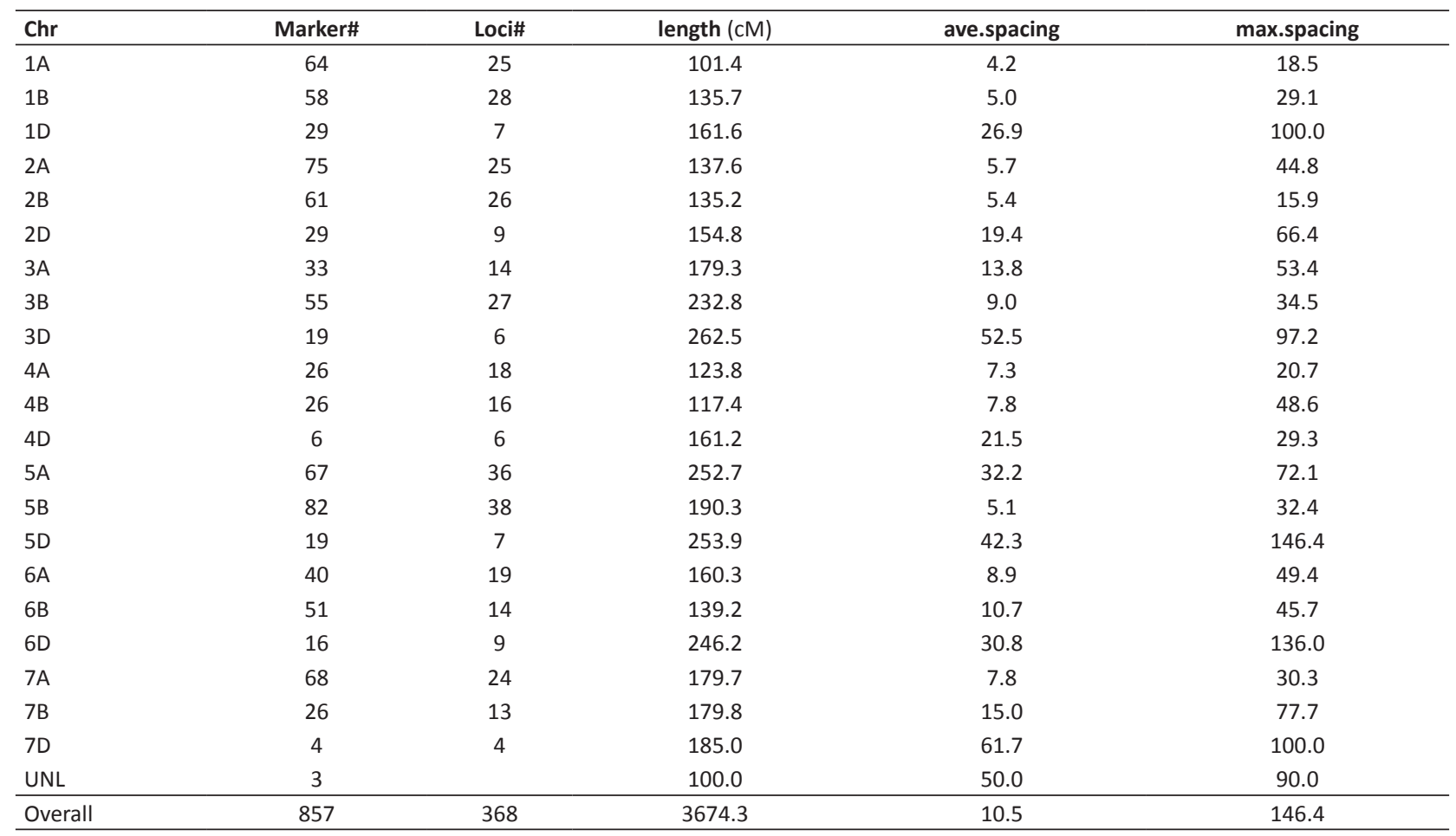

Table 2. QTL for spike fertility index detected in the B10xKCJ RIL population using BLUPS

\begin{tabular}{|c|c|c|c|c|c|c|c|}
\hline QTL & $\mathrm{cM}^{a}$ & $\operatorname{LOD}^{b}$ & $\mathrm{Cl}^{\mathrm{c}}$ & Allele Donor & $\begin{array}{c}\mathbf{A E}^{d} \\
\left(\text { grains } \mathrm{g}^{-1} \text { ) }\right.\end{array}$ & Physical position & $\begin{array}{l}\text { Best SNP } \\
\text { marker }^{e}\end{array}$ \\
\hline$Q_{\text {sf.hfe, } A \text { AL } \ldots . . .}$ & 29.2 & 5.54 & $27.2 ; 32.6$ & B10 & 2.44 & $\sim 472 \mathrm{Mbp}$ & AX-94674955 \\
\hline$Q_{\text {sfbfe } 7 \mathrm{~A}}$ & 72.2 & 4.91 & $66.0 ; 81.1$ & B10 & 1.74 & $\sim 119 \mathrm{Mbp}$ & AX-94523322 \\
\hline
\end{tabular}

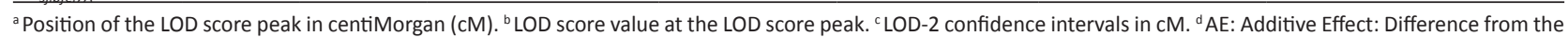
population mean. ${ }^{\text {SSNP }}$ marker associated with the LOD score peak. 
$1 \mathrm{~A}$

$1 \mathrm{~B}$

1D

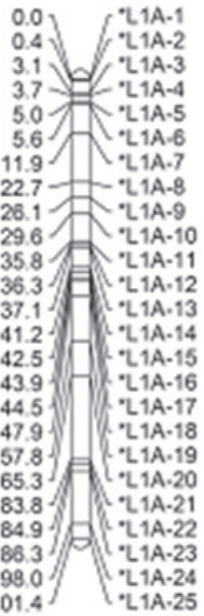

$3 \mathrm{~A}$

3B

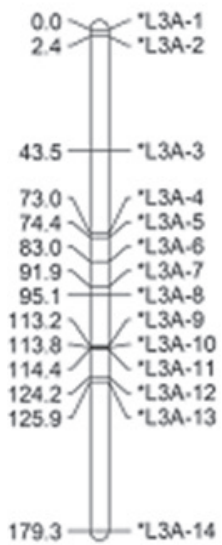

3D

151.6

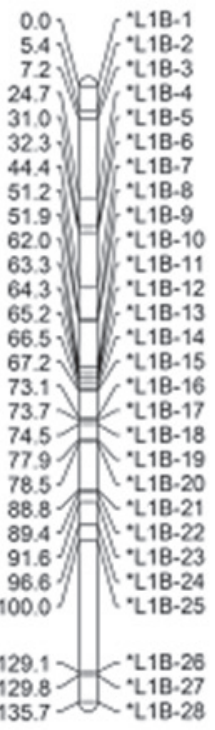

$161.6-$-L1D-7
2A
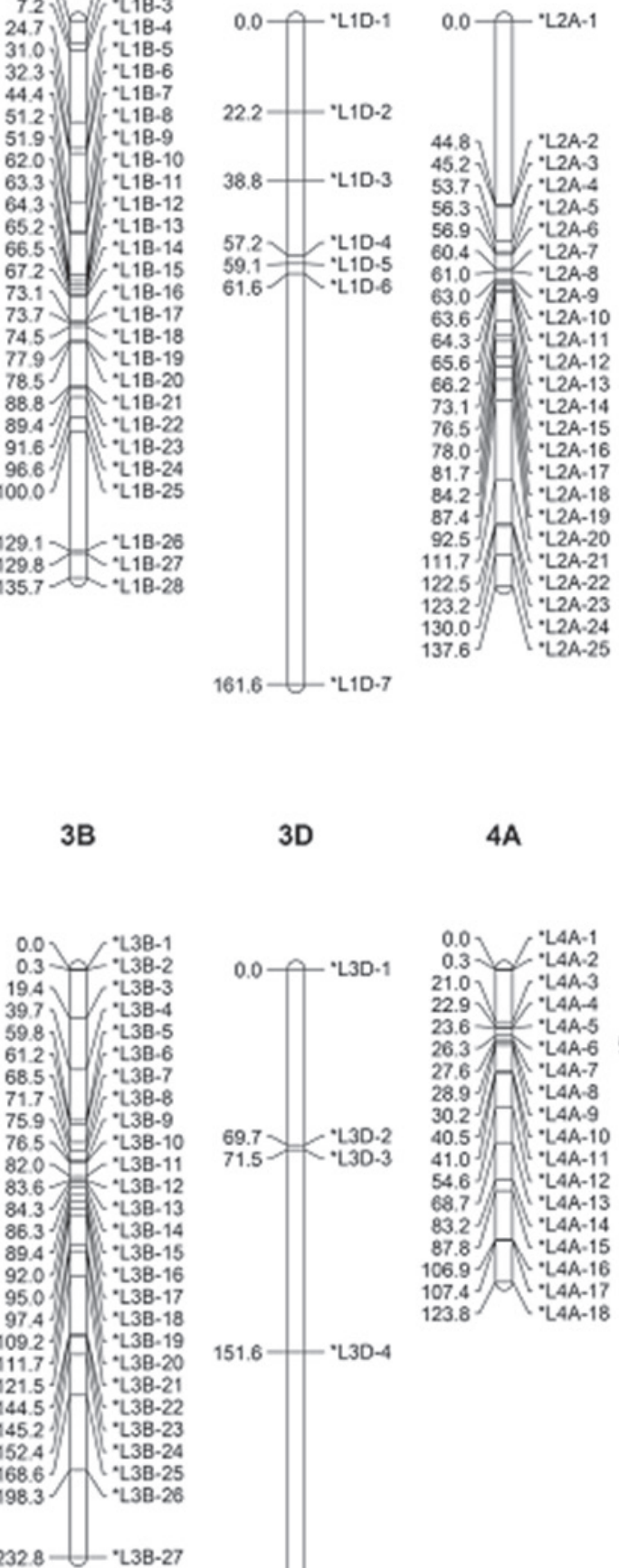

$4 \mathrm{~A}$

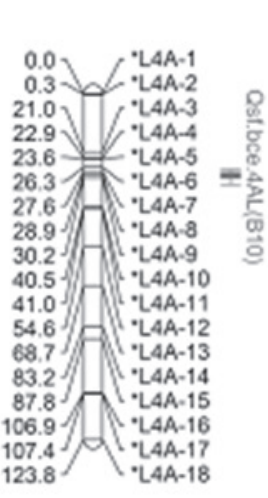

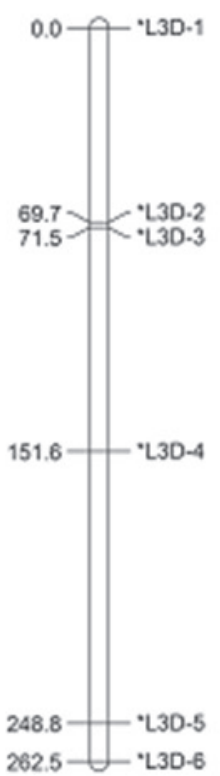

2B

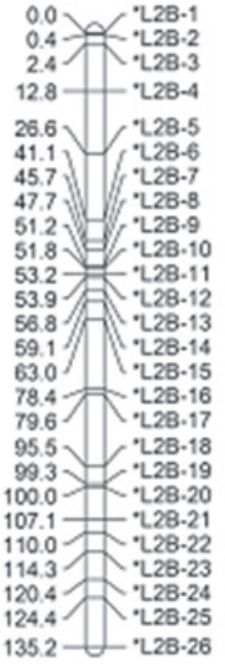

4B

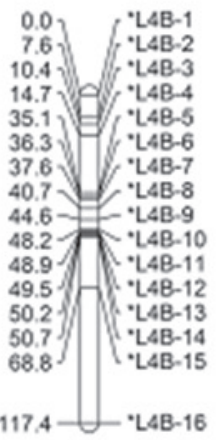

2D

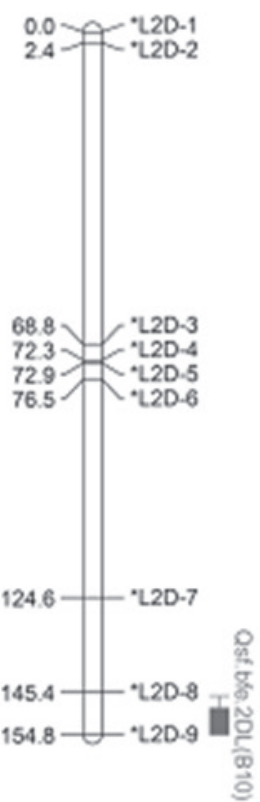

4D

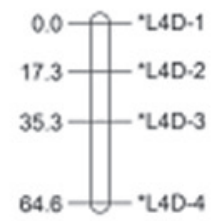


$5 A$

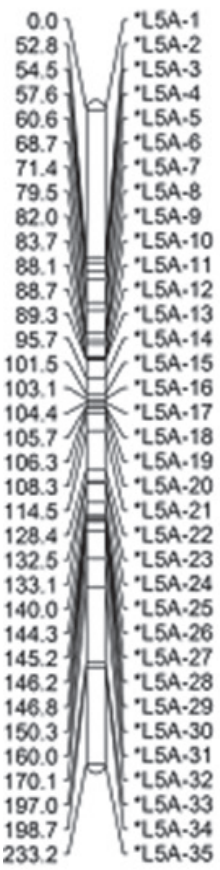

7A
5B

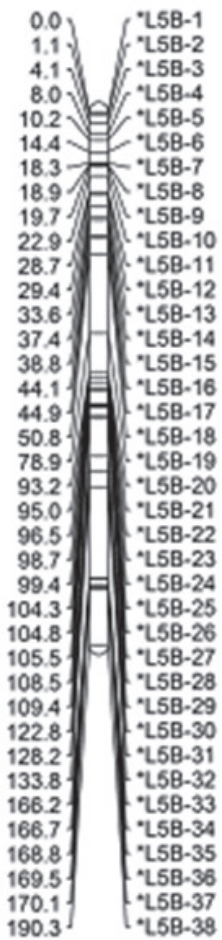

5D

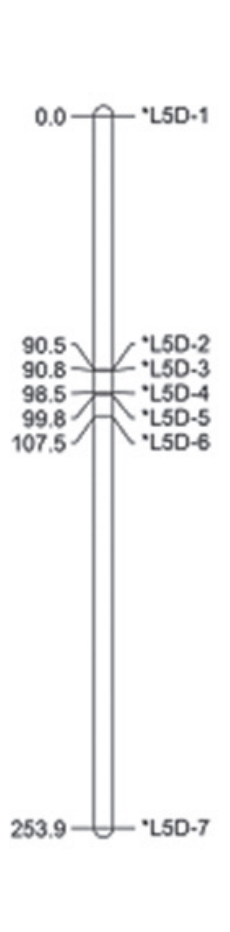

$6 \mathrm{~A}$

6B

6D
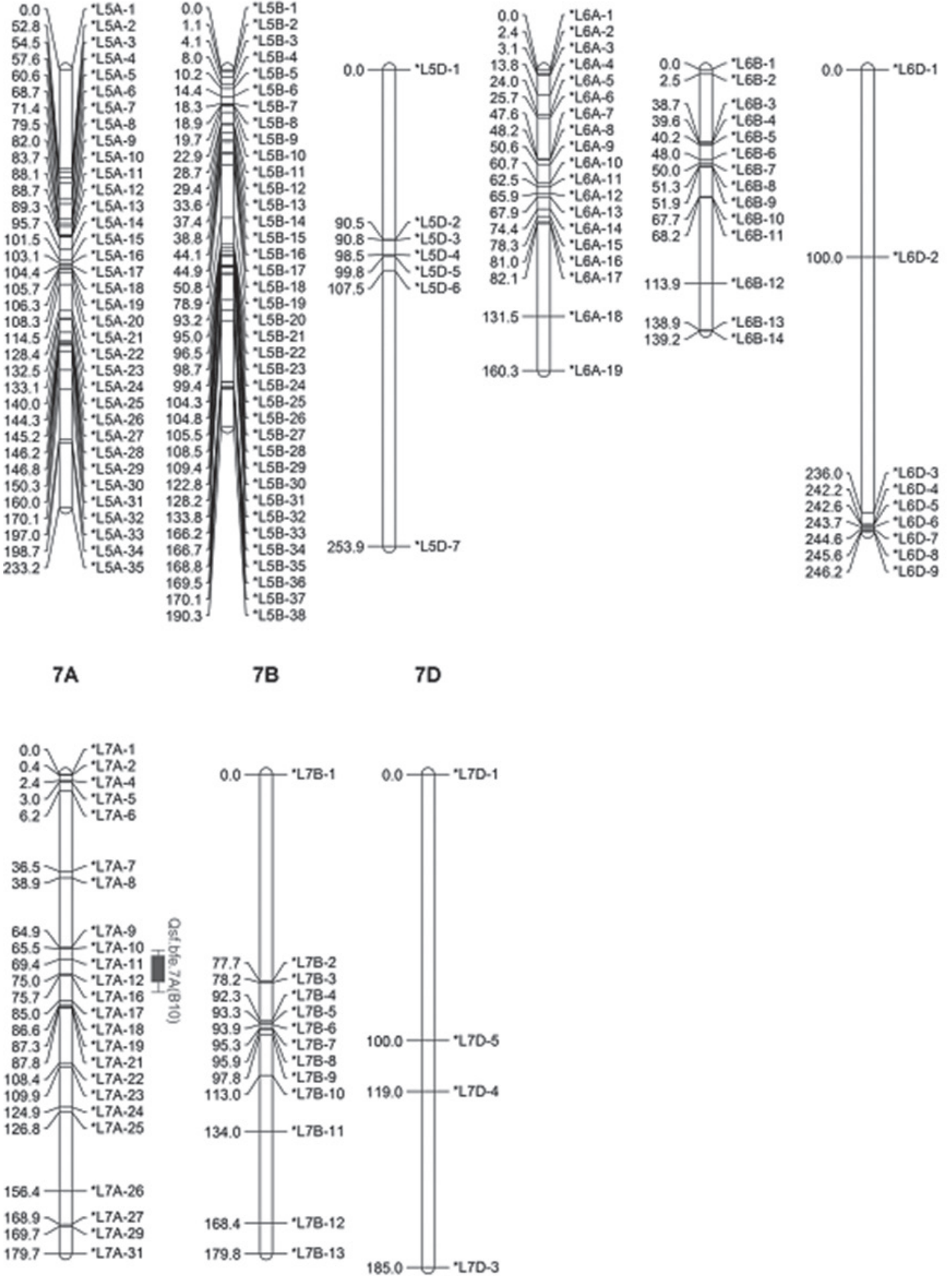

Figure S2. Linkage map of the B10xKCJ RIL population constructed using 857 SNP markers. Vertical boxes show QTL for SF. The error bars indicate the QTL confidence interval (LOD-2 decrease to each side of the LOD peak). 
Table 3. Average increase in spike fertility index (SF, grains $\left.\mathrm{g}^{-1}\right)$ with respect to the population mean as analyzed by the haplotype group at three QTL

\begin{tabular}{|c|c|c|c|}
\hline Haplotype group ${ }^{a}$ & $\mathbf{N}^{\mathbf{b}}$ & Average SF increase $\left(\text { grains g }^{-1}\right)^{c}$ & \\
\hline BBB & 5 & 4.9 & $\mathrm{a}$ \\
\hline$A B B$ & 12 & 4.7 & $a b$ \\
\hline BAB & 10 & 4.3 & $a b$ \\
\hline BBA & 12 & 3.8 & $a b$ \\
\hline BAA & 9 & 2.8 & $a b c$ \\
\hline$A B A$ & 12 & -3 & $a b c$ \\
\hline
\end{tabular}

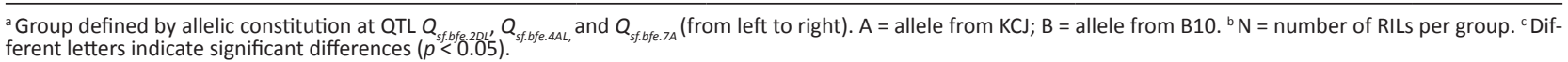

The results of haplotype analysis are shown in Table 3. The haplotype proportions corresponded with the expected values $\left(\chi^{2}=0.71\right)$. The best performing group, BBB (i.e., the one with B10 alleles at all three QTL), showed an average

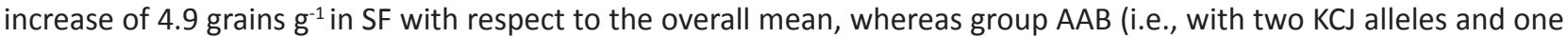
B10 allele) decreased average SF by 4.4 grains $\mathrm{g}^{-1}$ compared with the overall mean. The haplotype group BBB, as well as all three groups carrying at least two $B$ alleles, showed significantly higher SF increases than did group AAB. The AAA group was significantly different only from BBB. These results show the positive effect of B10 alleles on SF compared to the presence of KCJ alleles.

The present study provides information on genomic regions controlling SF in bread wheat. Peak SNP markers (Table 2) may be used to develop fine mapping populations in order to detect candidate genes which control the trait and to design strategies of marker-assisted selection for a complex quantitative trait such as grain yield.

\section{ACKNOWLEDGEMENTS}

We thank members of the Grupo Trigo Balcarce (Unidad Integrada Balcarce) for help with the experiments and technical assistance. Scholarships granted to M.P. Alonso and M. F. Franco by CONICET and partial funding by INTA (PNBIO 1131042), are acknowledged. This work is part of a thesis by M.P. Alonso in partial fulfillment of the requirements for a Doctor's degree (Facultad de Ciencias Agrarias, Universidad Nacional de Mar del Plata, Argentina).

\section{REFERENCES}

Abbate PE, Andrade FH, Lazaro L, Bariffi JH, Berardocco HG, Inza VH and Marturano F (1998) Grain yield increase in recent Argentine wheat cultivars. Crop Science 38: 1203-1209.

Abbate PE, Pontaroli AC, Lázaro L and Gutheim F (2013) A method of screening for spike fertility in wheat. Journal of Agricultural Science 151: $322-330$.

Allen AM, Winfield MO, Burridge AJ, Downie RC, Benbow HR, Barker GL, Wilkinson PA, Coghill J, Waterfall C, Davassi A and Scopes G (2017) Characterization of a wheat breeders' array suitable for highthroughput SNP genotyping of global accessions of hexaploid bread wheat (Triticum aestivum). Plant Biotechnology Journal 15: 390-401.

Alonso MP, Mirabella NE, Panelo JS, Cendoya MG and Pontaroli AC (2018) Selection for high spike fertility index increases genetic progress in grain yield and stability in bread wheat. Euphytica 214: 112.

Altschul SF, Gish W, Miller W, Myers FW and Lipman DJ (1990) basic local alignment search Tool. Journal of Molecular Biology 215: 403-410.
Appels R, Eversole K, Feuillet C, Keller B, Rogers J, Stein N, Pozniak CJ, Choulet F, Distelfeld A, Poland J and Ronen G (2018) Shifting the limits in wheat research and breeding using a fully annotated reference genome. Science 361(6403): eaar7191.

Basile, M, Ramírez I, Crescente J, Conde M, Demichelis M, Abbate P, Rogers W, Pontaroli A, Helguera M and Vanzetti L (2019) Haplotype block analysis of an Argentinean hexaploid wheat collection and GWAS for yield components and adaptation. BMC Plant Biology 19: 553.

Beavis WD (1998) QTL analyses: power, precision, and accuracy. Molecular Dissection of Complex Traits 1998: 145-162.

Börner A, Schumann E, Fürste A, Cöster H, Leithold B, Röder M and Weber W (2002) Mapping of quantitative trait loci determining agronomic important characters in hexaploid wheat (Triticum aestivum L.). Theoretical and Applied Genetics 105: 921-36.

Broman KW, Wu H, Sen S and Churchill GA (2003) R/qtl: qtl mapping in experimental crosses. Bioinformatics 19: 889-890.

Cavalcanti JJ, Santos FH, Silva FP and Pinheiro CR (2012) QTL detection of yield-related traits of cashew. Crop Breeding and Applied 


\section{Biotechnology 12: 60-66.}

CIMMYT (2019) Food security. Available at <https://www.cimmyt.org/ news/food-security/>. Accessed on September 15, 2019.

Ellis M, Spielmeyer W, Gale K, Rebetzke G and Richards R (2002) “Perfect" markers for the Rht-B1b and Rht-D1b dwarfing genes in wheat. Theoretical and Applied Genetics 105: 1038-1042.

Ferrante A, Cartelle J, Savin R and Slafer GA (2017) Yield determination, interplay between major components and yield stability in a traditional and a contemporary wheat across a wide range of environments. Field Crops Research 203: 114-127.

Ferrante A, Savin R and Slafer GA (2012) Differences in yield physiology between modern, well adapted durum wheat cultivars grown under contrasting conditions. Field Crops Research 136: 52-64.

Fischer RA (1984) Growth and yield of wheat. In: Potential Productivity of Field Crops Under Different Environments, International Rice Research Institute, Los Baños. W.H. Smith, S.J. Bante (Eds.), pp. 129-154

Fischer RA and Rebetzke GJ (2018) Indirect selection for potential yield in early-generation, spaced plantings of wheat and other small-grain cereals: a review. Crop and Pasture Science 69: 439-459.

Foulkes J, Rivera C, Trujillo E, Sylvester-Bradley R and Reynolds M (2015) Achieving a step-change in harvest index in high biomass wheat cultivars. TRIGO (Wheat) Yield Potential: 31-35.

Gerard GS, Alqudah A, Lohwasser U, Börner A and Simón MR (2019) Uncovering the genetic architecture of fruiting efficiency in bread wheat: a viable alternative to increase yield potential. Crop Science 59: 1-17.

Golan G, Ayalon I, Perry A, Zimran G, Ade-Ajayi T, Mosquna A, Distelfeld A and Peleg Z (2019) GNI-A1 mediates trade-off between grain number and grain weight in tetraploid wheat. Theoretical and Applied Genetics 132(8): 2353-2365.

Guo Z, Chen D, Alqudah AM, Röder MS, Ganal MW and Schnurbusch T (2017) Genome-wide association analyses of 54 traits identified multiple loci for the determination of floret fertility in wheat. New Phytologist 214: 257-270.

Haymes KM (1996) Mini-prep method suitable for a plant breeding program. Plant Molecular Biology Reporter 14: 280-284.

Hussain W, Baenziger PS, Belamkar V, Guttieri MJ, Venegas JP, Easterly A, Sallam A and Poland J (2017) Genotyping-by-sequencing derived high-density linkage map and its application to QTL mapping of flag leaf traits in bread wheat. Scientific Reports 7: 16394.

Kumar N, Kulwal PL, Balyan HS and Gupta PK (2007) QTL mapping for yield and yield contributing traits in two mapping populations of bread wheat. Molecular Breeding 19: 163-177.

Li H, Hearne S, Bänziger M, Li Z and Wang J (2010) Statistical properties of QTL linkage mapping in biparental genetic populations. Heredity 105: $257-267$
Martino D, Abbate PE, Cendoya MG, Gutheim F, Mirabella NE and Pontaroli AC (2015) Wheat spike fertility: inheritance and relationship with spike yield components in early generations. Plant Breeding 134: 264-270.

McCartney CA, Somers DJ, Humphreys DG, Lukow O, Ames N, Noll J, Cloutier S and Mccallum BD (2005) Mapping quantitative trait loci controlling agronomic traits in the spring wheat cross rl4452 $x^{\prime} \mathrm{ac}$ domain'. Genome 48: 870-883.

Mirabella NE, Abbate PE, Ramirez IA and Pontaroli AC (2016) Genetic variation for wheat spike fertility in cultivars and early breeding materials. Journal of Agricultural Science 154: 13-22.

Neumann K, Kobiljski B, Denčić S, Varshney RK and Börner A (2011) Genome-wide association mapping: a case study in bread wheat (Triticum aestivum I.). Molecular Breeding 27: 37-58.

Panelo JS, Alonso MP, Mirabella NE, Pontaroli AC (2019) Molecular marker analysis of spike fertility index and related traits in a bread wheat recombinant inbred line population. BAG, Journal of Basic and Applied Genetics (Online) 3:7-20.

Piepho HP, Möhring J, Melchinger AE and Büchse A (2008) Blup for phenotypic selection in plant breeding and variety testing. Euphytica 161: 209-228.

Pinheiro J, Bates D, DebRoy S, Sarkar D, Team RC. (2013) nlme: Linear and nonlinear mixed effects models. R package version 3(1):111.

Pradhan S, Babar MA, Robbins K, Bai G, Mason RE, Khan J, Shahi D, Avci M, Guo J, Hossain MM and Bhatta M (2019) Understanding the genetic basis of spike fertility to improve grain number, harvest index, and grain yield in wheat under high temperature stress environments. Frontiers in Plant Science 10: 1481.

Pretini N, Terrile II, Gazaba LN, Donaire GM, Arisnabarreta S, Vanzetti LS and González FG (2020a) A comprehensive study of spike fruiting efficiency in wheat. Crop Science 60: 1541-1555.

Pretini N, Vanzetti LS, Terrile II, Börner A, Plieske J, Ganal M, Röder M and González FG (2020b) Identification and validation of QTL for spike fertile floret and fruiting efficiencies in hexaploid wheat (Triticum aestivum L.). Theoretical and Applied genetics 133: 2655-2671.

R Core Team (2015) R: A language and environment for statistical computing. R Foundation for Statistical Computing, Vienna. Available at <https://www.r-project.or g/>. Accessed on April 14, 2018.

Ramirez IA, Abbate PE, Redi IW and Pontaroli AC (2018) Effects of photoperiod sensitivity genes $P p d-B 1$ and $P p d-D 1$ on spike fertility and related traits in bread wheat. Plant Breeding 137: 320-325.

Sadok IB, Celton JM, Essalouh L, El Aabidine AZ, Garcia G, Martinez S, Grati-Kamoun N, Rebai A, Costes E and Khadari B (2013) QTL mapping of flowering and fruiting traits in olive. PLoS ONE 8: e62831.

Sakuma S, Golan G, Guo Z, Ogawa T, Tagiri A, Sugimoto K, Bernhardt N, Brassac J, Mascher M, Hensel G, Ohnishi S, Jinno H, Yamashita Y, Ayalon I, Peleg Z, Schnurbusch T and Komatsuda T (2019) Unleashing floret fertility in wheat through the mutation of a homeobox gene. 
QTL mapping of spike fertility index in bread wheat

Proceedings of the National Academy of Sciences 116: 5182-5187.

Schön CC, Utz HF, Groh S, Truberg B, Openshaw S and Melchinger AE (2004) Quantitative trait locus mapping based on resampling in a vast maize testcross experiment and its relevance to quantitative genetics for complex traits. Genetics 167: 485-498.

Segura V, Durel CE and Costes E (2009) Dissecting apple tree architecture into genetic, ontogenetic and environmental effects: QTL mapping. Tree Genetics \& Genomes 5: 165-179.

Slafer GA, Elia M, Savin R, García GA, Terrile II, Ferrante A, Miralles DJ and González FG (2015) Fruiting efficiency: an alternative trait to further rise wheat yield. Food and Energy Security 4: 92-109.

Terrile II, Miralles DJ and González FG (2017) Fruiting efficiency in wheat (Triticum aestivum $\mathrm{L}$ ): trait response to different growing conditions and its relation to spike dry weight at anthesis and grain weight at harvest. Field Crops Research 201: 86-96.

Vales MI, Schön CC, Capettini F, Chen XM, Corey AE, Mather DE, Mundt CC, Richardson KL, Sandoval-Islas JS, Utz HF and Hayes PM (2005) Effect of population size on the estimation of qtl: a test using resistance to barley stripe rust. Theoretical and Applied Genetics 111: 1260-1270.

Valvo PJL, Miralles DJ and Serrago RA (2018) Genetic progress in Argentine bread wheat varieties released between 1918 and 2011: changes in physiological and numerical yield components. Field Crops Research 221: 314-321.

Vanzetti LS, Yerkovich N, Chialvo E, Lombardo L, Vaschetto L and Helguera M (2013) Genetic structure of Argentinean hexaploid wheat germplasm. Genetics and Molecular Biology 36: 391-399.

Verboon P, Chan A, Baggett J, McNeish D, Sabbe N, Bonett D, Moinester M, Gruijters S, Pat-EI R (2018) userfriendlyscience-package: Userfriendlyscience (UFS).

Wang H, Smith KP, Combs E, Blake T, Horsley RD and Muehlbauer GJ (2012b) Effect of population size and unbalanced data sets on QTL detection using genome-wide association mapping in barley breeding germplasm. Theoretical and Applied Genetics 124: 111-124.

Wang S, Basten CJ and Zeng ZB (2012a) Windows QTL cartographer 2.5. North Carolina State University, Department of Statistics, Raleigh. Available at $<$ http://statgen.ncsu.edu/qtlcart/WQTLCart.htm>. Accessed on May 7, 2018.

Yan L, Helguera M, Kato K, Fukuyama S, Sherman J and Dubcovsky J (2004) Allelic variation at the $\mathrm{Vrn}-1$ promoter region in polyploid wheat. Theoretical and Applied Genetics 109: 1677-86.

Zadoks JC, Chang TT and Konzak CF (1974) A decimal code for the growth stages of cereals. Weed Research 14: 415-21 